\title{
Improved blue light-emitting polymeric device by the tuning of drift mobility and charge balance
}

\author{
Byung Doo Chin, ${ }^{\text {a) }}$ Min Chul Suh, Seong Taek Lee, and Ho Kyoon Chung \\ Corporate R\&D Center, Samsung SDI Co., LTD., 428-5, Gongse-Ri, Kiheung-Eup, Yongin-City, \\ Gyeonggi-Do, 449-902, Korea \\ Chang Hee Lee \\ Department of Physics, Inha University, Inchon 402 751, Korea
}

(Received 27 October 2003; accepted 6 January 2004)

\begin{abstract}
We have prepared blue polymer-small molecule hybrid electroluminescence devices with improved efficiency and lower driving voltage by the statistical design method. Analysis of time-of-flight measurement shows that amorphous small molecule hole-transporter blended with a blue light-emitting polymer increases the field-dependent hole mobility, with transition from nondispersive to dispersive transport induced by the charge-trapping effect. Moreover, at the electroluminescent devices with different electron injection/transport layer $(\mathrm{LiF} / \mathrm{Al}, \mathrm{LiF} / \mathrm{Ca} / \mathrm{Al}$, and $\mathrm{Alq}_{3} / \mathrm{LiF} / \mathrm{Al}$ ), efficiency was further increased. We have analyzed that carrier mobility of a multilayered device can also be controlled by the change of electron injection and transport layers. We find that structural design and matching overall charge balance is an essential factor to improve both the operating voltage and efficiency of existing blue polymer devices. (C) 2004 American Institute of Physics. [DOI: 10.1063/1.1651644]
\end{abstract}

Light emitting polymers (LEPs) have great potential as materials for full-color flat panel display devices due to the easiness of solution processing and low-cost patterning methods. Therefore, several alternative patterning methods, such as excimer laser ablation, ${ }^{1}$ ink-jet printing, ${ }^{2}$ and micropatterning by cold welding, ${ }^{3}$ have been demonstrated. A more efficient method for patterning polymer light-emitting device (PLEDs) is laser induced thermal imaging (LITI) proposed by 3M (St. Paul, MN) and Samsung SDI (Suwon, Korea). ${ }^{4,5}$ Unlike the ink-jet technology, LITI is a solid-tosolid transferring process that requires, in general, the material within the transfer layer is conveyed from the "donor" to a receptor surface.

LITI can transfer the LEPs containing additive inert polymers and LEPs blended with optoelectronically active small molecules such as soluble hole and electron transporters ${ }^{6}$ so that it is a promising patterning technique for a high resolution and large size substrate. Our previous study revealed that $\{1,3,5$-tris[N,N-bis(4-methoxyphenyl)aminophenyl] benzene\} triphenylamine [TDAPB, from Bayer AG, with highest occupied molecular orbital (HOMO); $5.10 \mathrm{eV}$ (Ref. 7) and $5.30 \mathrm{eV}$ measured by RikenKeiki AC2] was found to be matched with most commercial blue LEPs. ${ }^{8}$

Control of charge-carrier mobility is another important factor for a design of better PLEDs, which is closely related to the charge balance for injection and transport of hole and electron. Moreover, understanding the charge and field distribution (e.g., formation of interfacial space charge) is essential to improve the performance and stability of devices. An ultraviolet photoelectron spectroscopy study to measure the work function of monolayer amount $\mathrm{LiF}$ on aluminum

${ }^{a)}$ Electronic mail: bdchin@samsung.com revealed the efficient electron injection via the reduction of barrier height as increasing LiF thickness. ${ }^{9}$ Improving efficiency by the reduction of electron injection barrier height (differing $\mathrm{LiF}$ thickess at $\mathrm{LiF} / \mathrm{Al}$ or $\mathrm{LiF} / \mathrm{Ca} / \mathrm{Al}$ ) was also reported with built-in potential measurement of electroabsorption. ${ }^{10-12}$ Effect of such injection barrier reduction on the carrier mobilities can be studied by a transient electroluminescence (TEL) experiment. However, buildup of internal space charge at interfaces and the difference of hole/ electron injection make the interpretation difficult at the multilayered devices. ${ }^{13}$

In this letter, a statistical method was used to fabricate an optimized blue polymer-small molecule hybrid emitting layer. Established formulation is ready for the highresolution patterning (LITI) for full color devices. We have employed the time-of flight (TOF) and TEL technique to study the charge carrier mobility of blue PLED, which suggest the optimum carrier mobility levels.

Blue light-emitting devices were fabricated on $\mathrm{UV}-\mathrm{O}_{3}$ treated 180-nm-thick indium tin oxide (ITO) substrates covered by $80 \mathrm{~nm}$-PEDOT:PSS (Baytron ${ }^{\circledR}$ P TP CH8000, Bayer AG). The hybrid emitter containing polyfluorene-type blue LEP (Lumation* BlueJ Light-Emitting Polymers, Trademark of Dow Chemical Company, BlueJ) small molecular hole transporter (TDAPB), and inert polymer that further helps precise LITI-patterning (polyacenaphthylene, from Aldrich) (PANa), was spin coated from 1.0 wt $\%$ toluene solution blended. The electron transport layer and cathode were evaporated at pressures less than $10^{-7}$ Torr the thickness of each layer was $5 \mathrm{~nm}$ for $\mathrm{Alq}_{3}, 3 \mathrm{~nm}$ for $\mathrm{LiF}, 8 \mathrm{~nm}$ for $\mathrm{Ca}$, and $250 \mathrm{~nm}$ for Al. The thickness was measured with a calibrated oscillating crystal monitor. The annealing process of the emitting layer $\left(90^{\circ} \mathrm{C}\right.$ for $\left.60 \mathrm{~min}\right)$ was performed before $\mathrm{Alq}_{3}$ or cathode evaporation. 


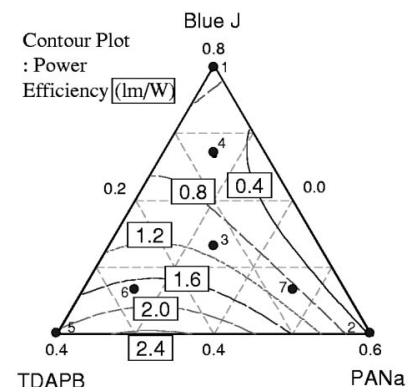

(a)

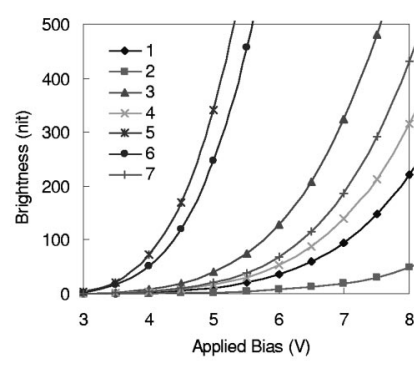

(b)
FIG. 1. Design of a three-component mixture of Blue LEP (BlueJ), HTL (TDAPB), and inert polymer (PANa) to achieve lower driving voltage as well as high efficiency. (a) The seven points indicates the position of each mixture with the concentration, for example, point 5 occupies the mixture ratio of BlueJ/TDAPB/PANa 4/4/2. Lines of contour plot show the statistical distribution of power efficiency at $150 \mathrm{Cd} / \mathrm{m}^{2}$, and dotted straight lines correspond to each composition of three components. (b) Luminance plot of the three-component system as a function of the driving voltage.

In Fig. 1(a), luminance-voltage characteristics of PLED devices using BlueJ/TDAPB/PANa ternary blends and $\mathrm{LiF} / \mathrm{Al}$ cathode were depicted. In the three-component mixture diagram [Fig. 1(b)], which was designed by MINITAB ${ }^{\circledR}$ software, contour lines of power efficiency at the specified brightness $\left(1 \mathrm{~m} / \mathrm{W}\right.$, measured at $\left.150 \mathrm{Cd} / \mathrm{m}^{2}\right)$ were described. It was clearly visible that brightness as well as current density increases as the fraction of TDAPB in the mixture increases. Within the range of selected composition, BlueJ/TDAPB/PANa 4/4/2 exhibited the lowest operating voltage and reasonable power efficiency $(\sim 2.0 \mathrm{~lm} / \mathrm{W})$ with CIE1931 $[x=0.14, y=0.17]$. In addition, distribution of the contour line predicted the maximum power efficiency at the composition at BlueJ/TDAPB/PANa 4/3/3.

Figure 2 illustrates the result of TOF experiments for a single layer of polymer-small molecule hybrid emitter. From the $\mathrm{N}_{2}$ laser $(337.5 \mathrm{~nm})$ with short duration $(300 \mathrm{ps})$, the sandwiched emitting layer $(1 \mu \mathrm{m}$ thickness and 4 $\mathrm{mm}^{2}$ active area) between ITO and Al was optically excited. The transient current was measured across the load resistor using a digital storage oscilloscope. At a field of $E=3.5$

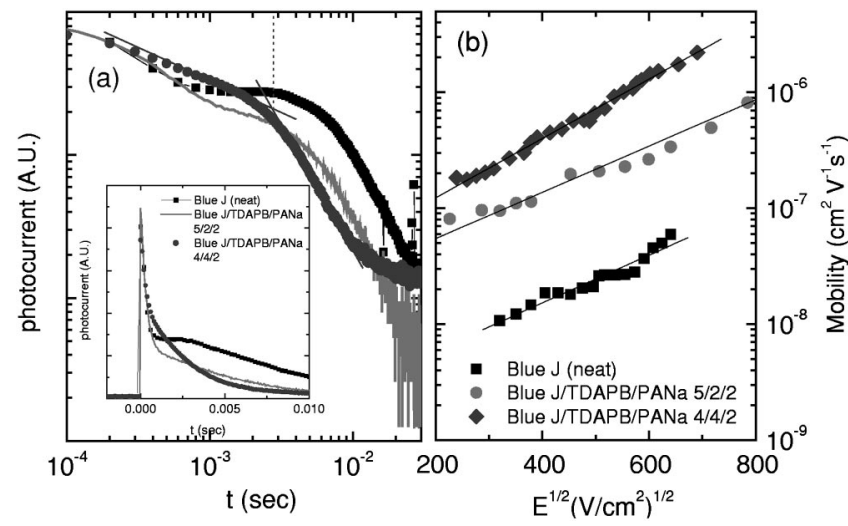

FIG. 2. (a) The room-temperature time-of-flight transient for a Blue LEP (BlueJ) and BlueJ/TDAPB/PANa blends. The film thickness was 0.9-1.05 $\mu \mathrm{m}$ and the measurement was performed in the range of electric field $E$ $=4 \times 10^{-4} \sim 10 \times 10^{-4} \mathrm{~V} / \mathrm{cm}$. The square lines are data for neat BlueJ, lines are for BlueJ/TDAPB/PANa 5/2/2, and diamonds are for BlueJ/TDAPB/ $\mathrm{PANa} 4 / 4 / 2$. Inset figure is the linear plot of the identical photocurrent data. (b) Hole mobilities as a function of the square of electric field strength.

Lines are linear fit to get the Poole-Frenkel parameters. For voltage pulses with different amplitude (6.0-13.0 V),
Downloaded 09 Nov 2009 to 147.46.118.89. Redistribution subject to AIP license or copyright; see http://apl.aip.org/apl/copyright.jsp $\times 10^{6} \mathrm{~V} / \mathrm{cm}$ and $300 \mathrm{~K}$, the neat BlueJ polymer showed a typical nondisperse hole transport signal with a clear current plateau, as seen in Fig. 2(a). This clear plateau behavior appears at the case of conjugated homopolymer $[\operatorname{poly}(9,9-\text { dioctylfluorene })]^{14}$ and several copolymers ffluorene-triarylamine, such as poly[9,9 - dioctylfluorenecobisN,N - (4 - butylphenyl) - bis - N,N phenyl-1,4-phenylenediamine]\}. ${ }^{15}$ Such a plateau tends to be disappeared as the blending ratio of TDAPB increases. Since the addition of TDAPB increases the current density of the device, the required electric field at the similar magnitude of the current peak is decreased as the TDAPB concentration increases. The delay time can be estimated at the junction of the slope guideline, which is distinguished by the arrival of photoexcited electrons. Field dependence of hole mobility data is plotted for neat BlueJ and blend composition of TDAPB/PANa 5/2/2; 4/4/2 [Fig. 2(b)], this log-linear scale plot showed approximate linear dependence on the square root of the electric field. For usual amorphous organic semiconductors, it can be attributed to the effects of disorder on charge transport. ${ }^{15,16}$ Increased hole mobility explains the decrease in operating voltage [Fig. 1(a)] at the higherconcentration region of TDAPB. However, due to a slightly lower ionization potential HOMO of TDAPB compared to BlueJ (5.5 eV, by Riken-Keiki AC2), it might also act as a hole trap at the charge-transport process, ${ }^{17}$ which can otherwise limit the passing current and therefore, better power efficiency as shown in Fig. 1(b).

The measured hole mobility by the TOF experiment in this study seems to obey the Poole-Frenkel form ${ }^{15}$

$$
\mu=\mu_{0} \exp (\beta \sqrt{E}),
$$

where $\mu_{0}$ is the zero field mobility (extrapolated) and $\beta$ is Poole-Frenkel factor. The addition of hole-transport material into the light-emitting polymer resulted in the increase of disorder, hence, the continuous decay of the photocurrent occurs at a faster rate. For neat BlueJ, $\mu_{0}=2.29$ $\times 10^{-9} \mathrm{~cm}^{2} / \mathrm{V} \mathrm{s}$ and $\beta=4.75 \times 10^{-3}(\mathrm{~cm} / \mathrm{V})^{-1 / 2}$. BlueJ/ TDAPB/PANa $5 / 2 / 2$ showed that $\mu_{0}=2.18 \times 10^{-8} \mathrm{~cm}^{2} / \mathrm{V} \mathrm{s}$ and $\beta=4.6 \times 10^{-3}(\mathrm{~cm} / \mathrm{V})^{-1 / 2}$. For BlueJ/TDAPB/PANa $4 / 2 / 2$, a further increase of $\mu_{0}=3.79 \times 10^{-8} \mathrm{~cm}^{2} / \mathrm{V} \mathrm{s}$ and $\beta$ $=5.59 \times 10^{-2}(\mathrm{~cm} / \mathrm{V})^{-1 / 2}$ was shown.

Figure 3 shows the difference of luminance-voltage (a) and efficiency data (b) when the electron injection or transport are structurally facilitated (for BlueJ/TDAPB/PANa $4 / 4 / 2$ hybrid emission layer). As reported in the literature, ${ }^{12}$ the $\mathrm{LiF} / \mathrm{Ca} / \mathrm{Al}$ trilayer cathode increases power efficiency (up to $3.0 \mathrm{~lm} / \mathrm{W}$ ) showing a lower operating voltage with our device. Another modification is the use of electron transport layer $\left(5 \mathrm{~nm} \mathrm{Alq}_{3}\right)$ evaporated on top of the blended emission layer, which does not significantly change the color purity of blue emission (CIE1931 $y<0.20$ ). In this case, the operating voltage is somewhat increased and, hence, lower power efficiency is obtained compared to the device using $\mathrm{LiF} / \mathrm{Al}$ cathode. This can be attributed to the energy level of lowest occupied molecular orbital (LUMO) offset at the interface and possible buildup of the space charge. Figure 3(c) is the normalized TEL signal of the device using BlueJ/TDAPB/ PANa (4/4/2) as an emission layer and $\mathrm{LiF} / \mathrm{Ca} / \mathrm{Al}$ cathode. For voltage pulses with different amplitude $(6.0-13.0 \mathrm{~V})$, 


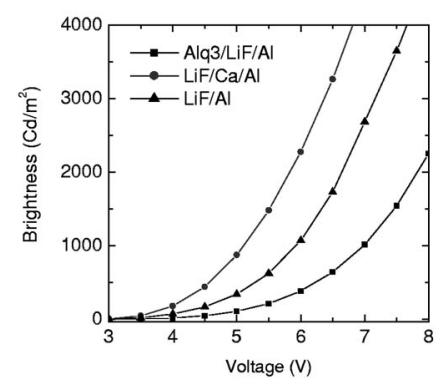

(a)

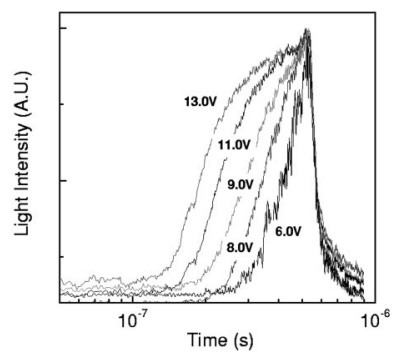

(c)

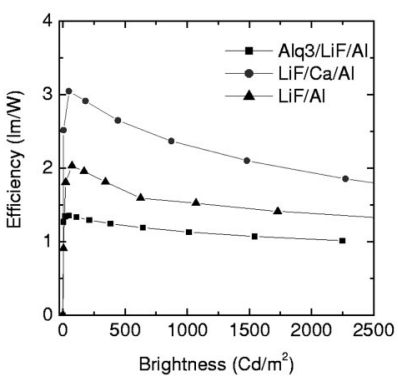

(b)

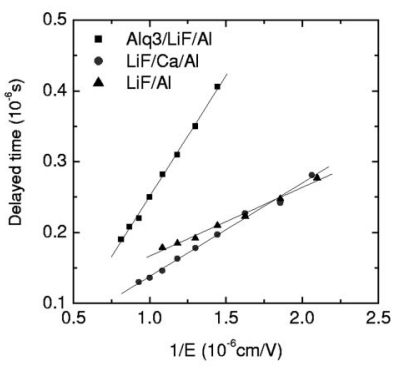

(d)
FIG. 3. Luminance plot (a) and power efficiency (b) for BlueJ/TDAPB/ PANa blend (4/4/2) with different cathode/electron transport layer. (c) Normalized TEL signal of BlueJ/TDAPB/PANa blend (4/4/2) using $\mathrm{LiF} / \mathrm{Ca} / \mathrm{Al}$. (d) Delayed time as a function of 1/E (TEL data).

delayed time is detected at the onset point of light intensity signal (extrapolated). The TEL charge mobility of each device are obtained as: ${ }^{13}$

$$
\mu=\frac{d}{\left(t_{d} E\right)}, \quad E=\frac{V}{d} .
$$

Here $d$ corresponds to the total thickness of active organic materials (thickness of PEDOT:PSS plus the emission layer), $E$ is the applied electric field, and $t_{d}$ is the measured delayed time. Charge carrier mobilities deduced from delayed time versus $E$ data were $3.81 \times 10^{-5} \mathrm{~cm}^{2} / \mathrm{V} \mathrm{s}\left(\mathrm{Alq}_{3} / \mathrm{LiF} / \mathrm{Al}\right)$, $9.06 \times 10^{-5} \mathrm{~cm}^{2} / \mathrm{V} \mathrm{s}(\mathrm{LiF} / \mathrm{Ca} / \mathrm{Al})$, and $1.34 \times 10^{-4} \mathrm{~cm}^{2} / \mathrm{V} \mathrm{s}$ ( $\mathrm{LiF} / \mathrm{Al})$, respectively. Hence, the change of the emitting layer/cathode interface affects the apparent charge mobility of the device obtained by the delay time-TEL experiment. Analysis of delay time by TEL is even more complicated at the multilayered device due to the space charge accumulation at the interface, with several reports showing that delay time by TEL is governed not by simple charge transport but by the reach of slower charge carrier (mostly electrons) and recombination with the hole already accumulated at the organic interface. ${ }^{18,19}$ In that case, determination of carrier mobility by delay time should be applied for a very limited situation. Possible accumulation of a minority (electron) carrier at the emitting layer/Alq ${ }_{3}$ explains well the reduced TEL mobility, but comparison of the $\mathrm{LiF} / \mathrm{Al}$ and $\mathrm{LiF} / \mathrm{Ca} / \mathrm{Al}$ structure is rather complicated. If the injection of the electron at the cathode/emitting layer is sufficiently fast, TEL charge mobility may also reflect the transport of a major carrier through the emitting layer, which can then be affected by the transport of the opposite charge (electron). The discrepancy of charge carrier mobility based on TOF and TEL measurement in our study is, of course, due to the complicated device structure and interfacial effect at the real electroluminescence device.

In conclusion, we have found optimum composition and structure of polymer-small molecule hybrid device to achieve improved efficiency and driving voltage of the blue PLED. Balancing the charge transport by the structural method was found to be an essential technique to improve the performance of a blue PLED device for practical application.

The authors thank the Dow Chemical Company (Midland, MI) for the supply of LUMATION light-emitting polymer. B.D.C. expresses special thanks to Ki-Wook Kang at Inha University for the measurement of TOF and TEL experiments. Helpful discussions with Dr. Mu Hyun Kim and Dr. Nam Choul Yang are appreciated.

${ }^{1}$ S. Noach, E. Z. Faraggi, G. Cohen, Y. Avny, R. Neumann, D. Davidov, and A. Lewis, Appl. Phys. Lett. 69, 3650 (1996).

${ }^{2}$ T. R. Hebner, C. C. Wu, D. Marcy, M. H. Lu, and J. C. Sturm, Appl. Phys. Lett. 72, 519 (1998).

${ }^{3}$ C. Kim, P. E. Burrows, and S. R. Forrest, Science 288, 831 (2000).

${ }^{4}$ US Patent No. 5,521,0351 (1996); US Patent No. 6,114,088 (2000).

${ }^{5}$ US Patent No. 6,242,140 (2001).

${ }^{6}$ B. D. Chin, International Meeting on Information Display (IMID 2003) Digest, Taegu, Korea, 9-11 July 2003, pp. 163-166.

${ }^{7}$ M. Thelakkat, R. Fink, P. Poesch, J. Ring, and H.-W. Schmidt, Polym. Prepr. (Am. Chem. Soc. Div. Polym. Chem.) 38, 394 (1997).

${ }^{8}$ M. C. Suh, B. D. Chin, M. H. Kim, T. M. Kang, and S. T. Lee, Adv. Mater. (Weinheim, Ger.) 15, 1254 (2003).

${ }^{9}$ S. E. Shaheen, G. E. Jabbour, M. M. Morrell, Y. Kawabe, B. Kippelen, N. Peyghambarian, M. F. Nabor, R. Schlaf, E. A. Mash, and N. R. Armstrong, J. Appl. Phys. 84, 2324 (1998).

${ }^{10}$ R. Schlaf, B. A. Parkinson, P. A. Lee, K. W. Nebesny, G. Jabbour, B. Kippelen, N. Eyghambarian, and N. R. Armstrong, J. Appl. Phys. 84, 6729 (1998).

${ }^{11}$ T. M. Brown, R. H. Friend, I. Millard, D. Lacey, J. H. Burroughes, and F. Cacialli, Appl. Phys. Lett. 77, 3096 (2000).

${ }^{12}$ T. M. Brown, R. H. Friend, I. Millard, D. Lacey, J. H. Burroughes, and F. Cacialli, Appl. Phys. Lett. 79, 174 (2001).

${ }^{13}$ V. R. Nikitenko, Y. H. Tak, and H. Baessler, J. Appl. Phys. 84, 2334 (1998).

${ }^{14}$ M. Redecker, D. D. C. Bradley, M. Inbasekaran, and E. P. Woo, Appl. Phys. Lett. 73, 1565 (1998).

${ }^{15}$ M. Redecker, D. D. C. Bradley, M. Inbasekaran, W. W. Wu, and E. P. Woo, Adv. Mater. (Weinheim, Ger.) 11, 241 (1999).

${ }^{16}$ P. M. Borsenberger and D. S. Weiss, Organic Photoreceptors for Imaging Systems (Marcel Dekker, New York, 1993).

${ }^{17}$ D. Sainova, H. Fujikawa, U. Scherf, and D. Neher, Opt. Mater. (Amsterdam, Neth.) 12, 387 (1999).

${ }^{18}$ S. Barth, P. Muller, H. Riel, P. F. Seidler, W. Riess, H. Vestweber, and H. Baessler, J. Appl. Phys. 89, 3711 (2001).

${ }^{19}$ T. Oestergard, A. J. Pal, and H. Stubb, J. Appl. Phys. 83, 2338 (1998). 